\title{
Intuitionistic Fuzzy Analysis of Supply Chain Performance: A Focus on Solid Waste in The Dar Es SalaAm City
}

\author{
Erick P. Massami ${ }^{1,}$ Malima M. Manyasi ${ }^{2}$ and Eliamin A. Kassembe ${ }^{3}$ \\ ${ }^{1}$ Department of Science and Management, Dar es Salaam Maritime Institute, \\ Dar es Salaam, Tanzania. \\ ${ }^{2}$ Department of Maritime Transport, Dar es Salaam Maritime Institute, \\ Dar es Salaam, Tanzania. \\ ${ }^{3}$ Department of Science and Management, Dar es Salaam Maritime Institute, \\ Dar es Salaam, Tanzania.
}

\begin{abstract}
Solid waste generation in Dar es Salaam City has been increasing due to rapid population growth and economic development. Using a population growth rate of $4.3 \%$ and a generation rate of $0.815 \mathrm{~kg} / \mathrm{cap} / \mathrm{day}$, it is estimated that Dar es Salaam could be generating over 12,000 tonnes of solid wastes per day by 2025. The waste materials have the potential to cause adverse environmental impacts including odour nuisance, litter problems, adverse visual impacts, and vermin and pests. A sound solid waste management is a result of the efficient and effective management of the supply chain of solid wastes which is composed of waste generation, storage, transportation and disposal. In this study, we apply Intuitionistic Fuzzy Sets (IFS) to assess the contribution of each element to the Solid Waste Supply Chain (SWSC). The data was collected from a random sample of ninety five (95) respondents consisting of practitioners, researchers and community members. The computational results reveal that, the contribution in descending order to the underperformance of SWSC in Dar es Salaam City are Storage of solid waste, Collection of solid waste, Disposal of solid waste and Transportation of solid waste. This study will be of great help to environmentalists, town planners, researchers and policy makers.
\end{abstract}

\section{KEYWORDS}

Intuitionistic Fuzzy Sets, Analysis, Solid Waste, Supply Chain, Dar es Salaam City

\section{INTRODUCTION}

Solid waste generation in Dar es Salaam city has been increasing due to rapid population growth and economic development. Dar es Salaam (DSM) which is the largest industrial and commercial centre of Tanzania is expected to reach a population of 6.2 million by 2025 [1]. Extrapolations show that by 2030 Dar es Salaam will be the fifth largest city in Africa. In addition, more than seventy percent of the population in DSM live in unplanned and under-serviced areas. The Dar es Salaam Municipal Government (DMG) which is responsible for Solid Waste Management (SWM) is composed of the Dar es Salaam City Council (DCC) and the five contiguous municipal councils (Dar es Salaam Local Authorities) of Kinondoni, Ilala, Temeke, Kigamboni and Ubungo. The Dar es Salaam Local Authorities (DLAs) deals with city cleaning waste collection and fee collection at the households and the markets whereas DCC provides an adequate treatment infrastructure. Final disposal activities of solid waste in DSM city are carried out at Pugu 
International Journal of Fuzzy Logic Systems (IJFLS) Vol.8, No.4, October 2018.

Kinyamwezi Dump Site (PKDS). This is the only formal disposal facility in DSM with 65 hectares located in the outskirts of Ilala, west of the Julius Nyerere International Airport and $30 \mathrm{~km}$ from the city centre. It was estimated by the DLAs that, approximately 4,200 tonnes per day of solid waste were generated in DSM in 2011[1]. This represents a generation rate of $0.93 \mathrm{~kg} / \mathrm{cap} /$ day based on a population of 4.5 million [1]. Using a population growth rate of $4.3 \%$ and a generation rate of $0.815 \mathrm{~kg} / \mathrm{cap} /$ day it is estimated that DSM could be generating over 12,000 tonnes of solid waste per day by 2025[1].

The waste materials have the potential to cause adverse environmental impacts during generation, storage, transportation and disposal. More specifically, if not appropriately managed, generated solid waste may give rise to adverse environmental impacts which include odour nuisance if putrescible material is not collected on a frequent basis; wind-blown material causing litter problems; vermin and pests in the waste storage area if it is not well maintained and cleaned regularly; as well as adverse visual impacts.

The Solid Waste Management (SWM) analysis provides a sound basis for the design of measures intended to improve the SWM in the city. The improvement of the SWM would complement and supplement other similar efforts all of which have the overarching goal of improving public health and environmental protection in the city. A sound solid waste management is a result of the efficiency and effectiveness of the supply chain of solid waste which is composed of waste generation, storage, transportation and disposal. Thus, the assessment the contribution of each of these elements and sub-elements would give stakeholders the necessary information for wellversed decision making. Nonetheless, practitioners and researchers find difficult to assess qualitatively i.e. in linguistic terms the performance of factors and/or sub-factors due to fuzziness and uncertainty.

In this study we apply Intuitionistic Fuzzy Sets (IFS) to determine the contribution of factors and/or sub-factors to the supply chain performance for solid waste in DSM city. The paper is organized as follows: Section 2 gives a review of previous studies; Section 3 presents an overview of intuitionistic fuzzy sets; Section 4 proposes intuitionistic fuzzy evaluation approach and Section 5 applies IFS to determine the contribution of the factors and sub-factors influencing the supply chain performance of solid waste in DSM city. Lastly, Section 6 gives the conclusions.

\section{Review Of Previous Studies}

Solid waste management has been investigated by many scholars and practitioners. Agyeman et al. [2] demonstrate how a lack of attention to the role of urbanites in Municipal Solid Waste Management (MSWM) has contributed to poor state of Solid Waste Management (SWM). Adeniran et al. [3] present solid waste generation and characterization in the University of Lagos for a sustainable waste management. Liu et al. [4] apply both life-cycle inventory analysis and impact assessment to determine the advantages and disadvantages of each waste management strategy. Simatele et al. [5] present perspectives on the challenges of integrating solid waste management into the urban development and planning policy in Johannesburg, South Africa. Maalouf and El-Fadel [6] examine the carbon footprint of introducing a Food Waste Disposer (FWD) policy and its implications on solid waste and wastewater management with economic assessment of environmental externalities emphasizing potential carbon credit and increased sludge generation. Soni et al. [7] present a study based in India on Municipal solid waste management. Chifari et al. [8] propose an approach which builds on metabolic network theory and multi-scale integrated analysis of societal and ecosystem metabolism to generate informed deliberations about policies over Municipal Solid Waste Management. Fernández-González et al. [9] analyse the economic and environmental costs of different Municipal Solid Waste (MSW) to-Energy technologies in an area comprising of thirteen Municipalities in Southern Spain. Zhu and Huang [10] conduct optimization analysis of the solid waste management system under 
different contracting out situation by formulating and applying a Waste Management Privatization Model (WMPM) to compare the private and public services. Khoshnerisan et al. [11] propose a number of incorrect assumptions and methodologies employed in the analysis led to invalid results and conclusions reached from the article "Prognostication of energy use and environmental impacts for recycle system of municipal solid waste management". Liu et al. [12] compare four garbage treatment systems, including separate collection and transportation, sanitary landfills systems, fluidized bed incineration system, and the composting system in Beijing. Rajaeifar et al. [13] aim at comprehensively assessing electricity generation potentials from Municipal Solid Waste (MSW) using an integrated solid waste management system, while the consequent GHG emission reduction potentials as a result of their implementation are also explored.

Kumar and Samadder [14] review the current global scenario of Waste to Energy (WTE) technological options (incineration, pyrolysis, gasification, anaerobic digestion, and landfilling with gas recovery) for effective energy recovery and the challenges faced by developed and developing countries. Ibrahim and Mohamed [15] aim to improve solid waste management in Egypt by exploring the options by which solid waste can be sustainably managed, and reviewing international models of sustainable management systems. Melaré et al. [16] present a systematic review on scientific review on scientific publications concerning decision support systems applied to Solid Waste Management (SWM) using ICTs and OR. Gupta et al. [17] present an overview of current status of solid waste management in India which can help the competent authorities responsible for municipal solid waste management and researchers to prepare more efficient plans. Deus et al. [18] aim to evaluate the environmental impact of inserting a recycling, composting and integrated program in a region of Sao Paulo State in Brazil through the waste reduction model method simulation of greenhouse gases emission and energy use. Sukholtthaman et al. [19] state that a public-private-community partnership is a potential way to alleviate the impacts of ineffective waste management.

A sound analysis of waste management is reached after evaluating the performance of influential factors and sub-factors of SWSC. Since these factors and sub-factors are associated with uncertainty and vagueness, we resort to fuzzy based evaluation approaches. Nonetheless, Intuitionistic Fuzzy Sets (IFS) has been proven to be an effective tool for dealing with uncertainty and vagueness. The distinguishing feature and advantage of this approach over other vague methods is that it gives the assessor the flexibility to determine the degree of membership, the degree of non-membership and the hesitation margin.

On the other hand, there are many problems in the literature that are investigated under intuitionistic fuzzy environment. Wang et al. [20] investigate the technique for clustering analysis under intuitionistic fuzzy environment. Tooranloo and Ayatollah [21] propose a novel model for failure mode and effects analysis based on intuitionistic fuzzy approach and apply it to internet banking services. Liu et al. [22] propose a method based on the sentiment analysis technique and the intuionistic fuzzy set theory to support consumers' decisions more conveniently on online purchase. Peijia et al. [23] propose a thermodynamic method for Multi-Criteria Decision Making (MCDM) with intuitionistic fuzzy numbers (IFNs) and the empirical studies demonstrate that the proposed method can effectively solve the practical decision making problems. Pei [24] proposes a novel concept of intuitionistic fuzzy variable as an attempt to extend the uncertainty theory, which possesses a decent self-dual property compared with the fuzzy set theory. Huchang et al. [25] propose an intuitionistic fuzzy multiplicative best-worst method with intuitionistic fuzzy multiplicative preference relations for multi-criteria group decision making. Govindan et al. [26] use intuionistic fuzzy set theory to handle the linguistic imprecision and the ambiguity of human being's judgement in the automotive industry. Wang and Sun [27] apply intuitionistic fuzzy sets to evaluate risks in projects of energy management contract. Long and Geng [28] present a decision framework of photovoltaic module selection under interval-valued intuitionistic fuzzy 
environment and uses a case study to demonstrate its effectiveness. Kucukvar et al. [29] propose a fuzzy MCDM which uses intuitionistic fuzzy entropy and intuitionistic fuzzy averaging operators for pavement selection problem. Wu and Chen [30] propose the intuitionistic fuzzy ELECTRE method for solving multi-criteria decision-making problems which uses imperfect or insufficient knowledge of data. Wu et al. [31] use intuitionistic fuzzy set to select wind farm project plan. Büyüközkan et al. [32] propose an integrated approach including intuitionistic fuzzy sets with group decision making. Zavadskas et al. [33] propose an extended version of weighted aggregated sum product assessment with interval-valued intuitionistic fuzzy numbers to be applied in uncertain decision making environment.

From the literature we reveal that limited studies investigate Municipal Solid Waste Management (MSWM) under intuitionistic fuzzy environment. To the best of our knowledge none study investigates supply chain performance for solid waste in the Dar es Salaam city based on Intuitionistic Fuzzy Sets (IFS). This study therefore fills in the identified gap from the literature.

\section{OVERVIEW OF INTUITIONISTIC FUZZY SETS}

Intuitionistic Fuzzy Set (IFS) is an extension and generalization of the ordinary fuzzy set [34]. The IFS considers not only the degree of membership to a given set but also the degree of non-membership such that the sum of both values is less than one [35].

Definition 3.1: Let $X$ be a set (space), with a generic element of $X$ denoted by $x$ i.e. $\quad X=\{x\}$. Then a Fuzzy Set (FS) is defined by equation (1).

$$
A=\left\{\left(x, \alpha_{A}(x)\right) \mid x \in X\right\}
$$

where $\quad \alpha_{A}: X \rightarrow[0,1]$ is the membership function of the fuzzy set A, $\quad \alpha_{A}(x) \in[0,1] \quad$ is the degree of membership of the element $x$ to the set A.

Definition 3.2: For a set X, an IFS A in the sense of Atanassov [36] is given by equation (2).

$$
A=\left\{\left(x, \alpha_{A}(x), \beta_{A}(x)\right) \mid x \in X\right\}
$$

where the functions $\alpha_{A}: X \rightarrow[0,1]$ and $\beta_{A}: X \rightarrow[0,1]$ with the condition $0 \leq \alpha_{A}(x)+$ $\beta_{A} \leq 1, \forall x \in X$. The numbers, $\quad \alpha_{A}(x) \in[0,1]$ and $\beta_{A}(x) \in[0,1]$ denote the degree of membership and the degree of non-membership of the element $\mathrm{x}$ to the set A, respectively. For each Intuitionistic Fuzzy Set $A$ in $X$, the amount $\quad \gamma_{A}(x)=1-\left(\alpha_{A}(x)+\beta_{A}(x)\right)$ is called the degree of indeterminacy (hesitation part), which may cater to the membership value, non-membership value or both.

Generally, $\quad \gamma_{A}: X \rightarrow[0,1]$ and $0 \leq \gamma_{A}(x) \leq 1, \forall x \in X$.

Definition 3.3: Suppose we have the following:

X: $\quad$ a set of all potential respondents served with a questionnaire,

A: a set of all respondents who filled in the questionnaire,

$n_{S}(x)$ : The number of respondents who are in favour of the factor/sub-factor under consideration,

$n_{D}(x)$ : The number of respondents who are against the factor/sub-factor under consideration,

$n_{U}(x)$ : The number of respondents who are indecisive in relation to the factor/subfactor under consideration, 
$|A|: \quad$ The total number of respondents who filled the questionnaire when assessing the factor/sub-factor under consideration,

Now,

$$
\begin{aligned}
& \alpha_{A}(x)=\frac{n_{S}(x)}{|A|} \\
& \beta_{A}(x)=\frac{n_{D}(x)}{|A|} \\
& \gamma_{A}(x)=\frac{n_{U}(x)}{|A|}
\end{aligned}
$$

Thus,

$$
\left(\alpha_{A}(x), \beta_{A}(x), \gamma_{A}(x)\right)=\left(\frac{n_{S}(x)}{|A|}, \frac{n_{D}(x)}{|A|}, \frac{n_{U}(x)}{|A|}\right)
$$

Hence,

$$
A=\left\{\left(x, \frac{n_{S}(x)}{|A|}, \frac{n_{D}(x)}{|A|}, \frac{n_{U}(x)}{|A|}\right) \mid x \in X\right\}
$$

\section{INTUITIONISTIC FUZZY EvaluATION APPROACH}

We develop the Intuitionistic Fuzzy Evaluation Approach (IFEA) which consists of the following sequential steps:

Step 1: Establish Intuitionistic Fuzzy Judgement Scale i.e. Intuitionistic Fuzzy Assessment Scale. We develop a linguistic scale of three units namely, $n_{S}(x), n_{D}(x)$, and $n_{U}(x), \forall x \in X$.

Step 2: Establish a Judgement Matrix of the factors/sub-factors as given in table 1.

Table1. Judgement matrix of the factors/sub-factors.

\begin{tabular}{|c|c|c|c|}
\hline $\mathbf{F}_{\mathrm{m}}$ & $n_{S}{ }^{m}(\boldsymbol{x})$ & $n_{D}{ }^{m}(\boldsymbol{x})$ & $n_{U}{ }^{m}(\boldsymbol{x})$ \\
\hline $\mathrm{F}_{1}$ & $n_{S}{ }^{1}(x)$ & $n_{D}{ }^{1}(x)$ & $n_{U}{ }^{1}(x)$ \\
\hline $\mathrm{F}_{2}$ & $n_{S}{ }^{2}(x)$ & $n_{D}{ }^{2}(x)$ & $n_{U}{ }^{2}(x)$ \\
\hline$\vdots$ & $\vdots$ & $\vdots$ & $\ldots$ \\
\hline $\mathrm{F}_{M}$ & $n_{S}{ }^{M}(x)$ & $n_{D}{ }^{M}(x)$ & $n_{U}{ }^{M}(x)$ \\
\hline
\end{tabular}

$F_{m}: \quad$ Factor/sub-factor $\quad m \in\{1,2, \ldots M\}$,

$n_{S}{ }^{m}(x)$ : No. of respondents who are in favour of the factor/sub-factor $m \in\{1,2, \ldots M\}$,

$n_{D}{ }^{m}(x)$ : No. of respondents who are against the factor/sub-factor $m \in\{1,2, \ldots M\}$,

$n_{U}{ }^{m}(x)$ : No. of respondents who are indecisive in relation to the factor/sub-factor $m \in\{1,2, \ldots M\}$,

Step 3: Establish Intuitionistic Fuzzy Judgement Table of Importance (IFJTI) of the factors/subfactors under consideration. The IFJTI is table 2 presented below. 
Table 2. The IFJTI of the factors/sub-factors.

\begin{tabular}{|c|c|}
\hline $\mathbf{F}_{\mathrm{m}}$ & $\left(\alpha_{A}{ }^{m}(\boldsymbol{x}), \beta_{A}{ }^{m}(\boldsymbol{x}), \gamma_{A}{ }^{m}(\boldsymbol{x})\right)$ \\
\hline $\mathrm{F}_{1}$ & $\left(\alpha_{A}{ }^{1}(x), \beta_{A}{ }^{1}(x), \gamma_{A}{ }^{1}(x)\right)$ \\
\hline $\mathrm{F}_{2}$ & $\left(\alpha_{A}{ }^{2}(x), \beta_{A}{ }^{2}(x), \gamma_{A}{ }^{2}(x)\right)$ \\
\hline$\vdots$ & $\vdots$ \\
\hline $\mathrm{F}_{\mathrm{M}}$ & $\left(\alpha_{A}{ }^{M}(x), \beta_{A}{ }^{M}(x), \gamma_{A}{ }^{M}(x)\right)$ \\
\hline
\end{tabular}

Step 4: Determination of Weight of Factor/Sub-factor $m \in\{1,2, \ldots M\}$.

The weight of the factor/sub-factor $m$ is computed by taking into account the hesitation margin i.e. adding half of the indecisive margin to the membership function to get a more realistic value of the membership degree.

We define the Weight of Factor/Sub-factor $m$ as

$$
W_{F_{m}}=\frac{1}{2}\left[2 \alpha_{A}^{m}(x)+\gamma_{A}{ }^{m}(x)\right], \quad m \in\{1,2, \ldots M\}
$$

Step 5: Compute the Normalized Weight $\left({W_{F}}{ }^{N}\right)$

$$
W_{F_{m}}{ }^{N}=\frac{2 \alpha_{A}^{m}(x)+\gamma_{A}^{m}(x)}{\sum_{k=1}^{M}\left(2 \alpha_{A}{ }^{k}(x)+\gamma_{A}^{k}(x)\right)}, \quad \forall m, k \in\{1,2, \ldots M\}
$$

Step 5: Determination of the Overall Contribution of the Sub-factor.

The local contribution of factors is aggregated to obtain final contribution of the sub-factors as follows:

$$
O C_{F_{m n}}=W_{F_{m}}{ }^{N} \cdot W_{F_{m n}}{ }^{N}
$$

$O C_{F_{m n}}$ : The Overall contribution of the sub-factor $\left(F_{m n}\right)$;

$W_{F_{m}}{ }^{N}$ : Local contribution of $F_{m}$ with respect to the goal;

$W_{F_{m n}}{ }^{N}$ : Local contribution of $F_{m n}$ with respect to $F_{m}$.

\section{Application Of Intuitionistic Fuzzy Sets To Determine The Contribution Of The Factors And Sub-Factors Influencing The Supply Chain Performance Of Solid Waste In Dar Es SalaAm City}

Literature review and opinions of supply chain professionals reveal that a typical Solid Waste Supply Chain (SWSC) is a network of nodes (i.e. chain members) involved in the collection of solid waste, storage of solid waste, transportation of solid waste and disposal of solid waste. The nodes are the factors that influence the supply chain performance as solid waste move from the source (generation point) to the point of disposal. As the performance of a supply chain depends on the performance of its nodes (sub-systems), this study considers the nodes as the major factors that influence the efficiency and effectiveness of a supply chain. Thus, the four main factors and 
sub-factors that can affect the Supply Chain Performance of Solid Waste (SCPoSW) in Dar es Salaam City are shown in table 3.

Table 3. Influential Factors and Sub-factors for the SCPoSW in Dar es Salaam City.

\begin{tabular}{|c|c|}
\hline Factor $\left(\mathbf{F}_{\mathbf{m}}\right)$ & Sub-factor $\left(\mathbf{F}_{\mathrm{mn}}\right)$ \\
\hline \multirow{5}{*}{$\begin{array}{l}\mathbf{F}_{1}: \text { Collection of solid } \\
\text { waste }\end{array}$} & $\mathbf{F}_{11}$ : Availability of collection facilities \\
\hline & $\mathbf{F}_{12}:$ Competence and/or hygienic of the collection staff \\
\hline & $\mathbf{F}_{13}$ : Awareness of the public on solid waste management \\
\hline & $\begin{array}{l}\text { F }_{14} \text { : Quality of collection containers and conditions of areas around } \\
\text { them }\end{array}$ \\
\hline & $\mathbf{F}_{15}:$ Availability of sweepers and/or sanitation workers \\
\hline \multirow[t]{3}{*}{$\mathbf{F}_{2}:$ Storage of solid waste } & $\mathbf{F}_{21}:$ Availability of community bins (storage points) \\
\hline & $\mathbf{F}_{\mathbf{2 2}}$ : Segregation of solid waste \\
\hline & $\mathbf{F}_{\mathbf{2 3}}$ : Management of solid waste \\
\hline \multirow{4}{*}{$\begin{array}{l}\mathbf{F}_{3}: \text { Transportation of } \\
\text { solid waste }\end{array}$} & $\mathbf{F}_{31}:$ Adequacy of transportation vehicles \\
\hline & $\mathbf{F}_{\mathbf{3 2}}$ : Suitability of transportation vehicles \\
\hline & $\mathbf{F}_{\mathbf{3 3}}$ : Traffic congestion on transportation routes \\
\hline & $\mathbf{F}_{\mathbf{3 4}}:$ Skills of vehicle operators \\
\hline \multirow{4}{*}{$\begin{array}{l}\mathbf{F}_{\mathbf{4}}: \text { Disposal of solid } \\
\text { waste }\end{array}$} & $\mathbf{F}_{41}$ : Treatment of garbage at the dumping site \\
\hline & $\mathbf{F}_{\mathbf{4 2}}$ : Safety precautions at the dumping site \\
\hline & $\mathbf{F}_{\mathbf{4 3}}$ : Availability of compactor or graders at the site \\
\hline & $\mathbf{F}_{44}$ : Security at the dumping site \\
\hline
\end{tabular}

\subsection{Determination of the Contribution of the Factors/Sub-factors to the Supply Chain Performance of Solid Waste}

This study uses data from ninety five (95) assessors who were supplied with a survey questionnaire. This team comprises practitioners, academicians and community members around Pugu Kinyamwezi Dumping Site (PKDS) with a sound knowledge in solid waste management. The assessors' data is used to compose the Judgement matrix of the factors and/or sub-factors from which we compute the Intuitionistic Fuzzy Judgement Table of Importance (IFJTI).

\subsubsection{Contribution of the Influential Factors to the Supply Chain Performance of Solid Waste}

The assessors' results on the contribution of the factors to the supply chain performance of solid waste $(\mathrm{SCPoSW})$ gave the Judgement matrix in table 4. 
International Journal of Fuzzy Logic Systems (IJFLS) Vol.8, No.4, October 2018.

Table 4. Judgement Matrix of the Influential Factors to the SCPoSW.

\begin{tabular}{|c|c|c|c|}
\hline Factor $\left(\mathrm{F}_{\mathrm{m}}\right)$ & $n_{S}{ }^{m}(\boldsymbol{x})$ & $n_{D}{ }^{m}(\boldsymbol{x})$ & $n_{U}{ }^{m}(\boldsymbol{x})$ \\
\hline $\mathrm{F}_{1}$ & 7 & 87 & 1 \\
\hline $\mathrm{F}_{2}$ & 6 & 88 & 1 \\
\hline $\mathrm{F}_{3}$ & 10 & 79 & 6 \\
\hline $\mathrm{F}_{4}$ & 7 & 85 & 3 \\
\hline
\end{tabular}

We apply equation (6) to establish the Intuitionistic Fuzzy Judgement Table of Importance (IFJTI) as shown in table 5 .

Table 5. IFJTI for the Factors Influencing the SCPoSW.

\begin{tabular}{|c|c|c|c|}
\hline $\mathbf{F}_{\mathrm{m}}$ & \multicolumn{3}{|c|}{$\left(\alpha_{A}^{m}(\boldsymbol{x}), \beta_{A}^{m}(\boldsymbol{x}), \gamma_{A}^{m}(\boldsymbol{x})\right)$} \\
\hline $\mathrm{F}_{1}$ & $(0.07$, & 0.92 , & $0.01)$ \\
\hline $\mathrm{F}_{2}$ & $(0.06$, & 0.93, & $0.01)$ \\
\hline $\mathrm{F}_{3}$ & (0.11, & 0.83 , & $0.06)$ \\
\hline $\mathrm{F}_{4}$ & $(0.07$, & 0.90 , & $0.03)$ \\
\hline
\end{tabular}

We apply equation (8) to get the weight set of the factors for the supply chain performance of solid waste i.e. equation (11).

$W S_{F}=\left\{W_{F_{1}}=0.075, W_{F_{2}}=0.065, W_{F_{3}}=0.14, W_{F_{4}}=0.085\right\}$

We apply equation (9) to get the normalized weight set of the factors for the supply chain performance of solid waste i.e. equation (12).

$$
W S_{F}{ }^{N}=\left\{W_{F_{1}}{ }^{N}=0.205, W_{F_{2}}{ }^{N}=0.178, W_{F_{3}}{ }^{N}=0.384, W_{F_{4}}{ }^{N}=0.233\right\}
$$

Equation (12) reveals that the storage of solid waste is the least performing factor to the SCM of solid waste. This result is largely contributed by ineffective segregation of solid waste. The second least performing factor to the SWSC is the collection of solid waste which is aggravated by the inadequacy of collection facilities in the city and low quality of collection containers and conditions of areas around them. The third least performing factor to the SWSC is the disposal of solid waste which is largely contributed by ineffective safety precautions at the dumping site and ineffective security at the dumping site. On the other hand, transportation of solid waste is the most performing factor to the SWSC. This result is largely contributed by availability of qualified vehicle operators. More specifically, assessors believe that most vehicle operators have enough skills for the job i.e. most drivers have attended Driving schools and have valid driving licences. Nonetheless, the performance of all factors including the transportation of solid waste $\left(\mathrm{F}_{3}\right)$ is not full satisfactory since $n_{S}{ }^{m}(x) \neq|A|, \forall m \in\{1,2,3,4\}$. Thus, all interested parties to the SWM in DSM City are called to take measures that would make the SWSC optimal.

\subsubsection{Contribution of the Influential Factors to the Effective Collection of Solid Waste}

The experts assess the contribution of the factors to the effective collection of solid waste to give the Judgement Matrix (JM) in table 6. 
International Journal of Fuzzy Logic Systems (IJFLS) Vol.8, No.4, October 2018.

Table 6. The JM of the Influential Factors for the Collection of Solid Waste.

\begin{tabular}{|c|c|c|c|}
\hline Factor $\left(\mathbf{F}_{\mathrm{mn}}\right)$ & $\boldsymbol{n}_{S}{ }^{\boldsymbol{m} n}(\boldsymbol{x})$ & $\boldsymbol{n}_{\boldsymbol{D}}{ }^{\boldsymbol{m}}(\boldsymbol{x})$ & $\boldsymbol{n}_{U}{ }^{m n}(\boldsymbol{x})$ \\
\hline $\mathrm{F}_{11}$ & 4 & 85 & 6 \\
\hline $\mathrm{F}_{12}$ & 6 & 74 & 15 \\
\hline $\mathrm{F}_{13}$ & 13 & 72 & 10 \\
\hline $\mathrm{F}_{14}$ & 8 & 86 & 1 \\
\hline $\mathrm{F}_{15}$ & 39 & 56 & 0 \\
\hline
\end{tabular}

We apply equation (6) to establish the IFJTI as shown in table 7.

Table 7. The IFJTI for the Factors Influencing the Collection of Solid Waste.

\begin{tabular}{|c|c|c|c|}
\hline $\mathbf{F}_{\mathrm{mn}}$ & \multicolumn{3}{|c|}{$\left(\alpha_{A}^{m n}(\boldsymbol{x}), \beta_{A}^{m n}(\boldsymbol{x}), \gamma_{A}^{m n}(\boldsymbol{x})\right)$} \\
\hline$F_{11}$ & $(0.04$ & 0.90 & $0.06)$ \\
\hline$F_{12}$ & $(0.06$ & 0.78 & $0.16)$ \\
\hline $\mathrm{F}_{13}$ & (0.14, & 0.76 & $0.10)$ \\
\hline$F_{14}$ & $(0.08$ & 0.91, & $0.01)$ \\
\hline$F_{15}$ & $(0.41$ & 0.59 & $0.00)$ \\
\hline
\end{tabular}

We apply equation (8) to get the weight set of the Influential factors for the collection of solid waste i.e. equation (13).

$$
W S_{\mathrm{F}_{1}}=\left\{W_{F_{11}}=0.07, W_{F_{12}}=0.14, W_{F_{13}}=0.19, W_{F_{14}}=0.085, W_{F_{15}}=0.41\right\}
$$

We apply equation (8) to get the weight set of the Influential factors for the collection of solid waste i.e. equation (14).

$$
\begin{aligned}
W S_{\mathrm{F}_{1}}{ }^{N}=\left\{W_{F_{11}}{ }^{N}=0.078, W_{F_{12}}{ }^{N}=0.157, W_{F_{13}}{ }^{N}=0.212, W_{F_{14}}{ }^{N}=0.095, W_{F_{15}}{ }^{N}\right. & 0.458\}
\end{aligned}
$$

Equation (14) shows that the ineffective collection of solid waste is largely contributed by insufficiency of solid waste collection facilities. The second contributing factor to the ineffective collection of solid waste is low quality of collection containers and poor conditions of areas around them. Other factors contributing to the ineffective collection of solid waste to less degree are incompetence and/or unhygienic of collection staff and low awareness of the public on SWM. This calls for the DMG to make sure that the solid waste collection facilities in the DSM City are available and improve the conditions of the environment around the collection facilities.

\subsubsection{Contribution of the Influential Factors to the Effective Storage of Solid Waste}

The experts assess the contribution of the factors to the effective storage of solid waste to give the Judgement Matrix (JM) in table 8. 
International Journal of Fuzzy Logic Systems (IJFLS) Vol.8, No.4, October 2018.

Table 8. The JM of the Influential Factors for the Storage of Solid Waste.

\begin{tabular}{|c|c|c|c|}
\hline Factor $\left(\mathrm{F}_{\mathrm{mu}}\right)$ & $n_{S}{ }^{m n}(\boldsymbol{x})$ & $n_{D}{ }^{m n}(\boldsymbol{x})$ & $n_{U}{ }^{m n}(\boldsymbol{x})$ \\
\hline $\mathrm{F}_{21}$ & 7 & 84 & 4 \\
\hline $\mathrm{F}_{22}$ & 2 & 90 & 3 \\
\hline $\mathrm{F}_{23}$ & 4 & 86 & 5 \\
\hline
\end{tabular}

apply equation (6) to establish the IFJTI as shown in table 9.

Table 9. The IFJTI for the Factors Influencing the Storage of Solid Waste.

\begin{tabular}{|c|c|c|c|}
\hline$F_{m u}$ & \multicolumn{3}{|c|}{$\left(\alpha_{A}^{m n}(\boldsymbol{x}), \beta_{A}{ }^{m n}(\boldsymbol{x}), \gamma_{A}^{m n}(\boldsymbol{x})\right)$} \\
\hline $\mathrm{F}_{21}$ & $(0.07$, & 0.89, & $0.04)$ \\
\hline $\mathrm{F}_{22}$ & $(0.02$, & 0.95 & $0.03)$ \\
\hline $\mathrm{F}_{23}$ & $(0.04$, & 0.91, & $0.05)$ \\
\hline
\end{tabular}

We apply equation (8) to get the weight set of the Influential factors for the storage of solid waste i.e. equation (15).

$$
W S_{\mathrm{F}_{2}}=\left\{W_{F_{21}}=0.09, W_{F_{22}}=0.035, W_{F_{23}}=0.065\right\}
$$

We apply equation (9) to get the normalized weight set of the Influential factors for the storage of solid waste i.e. equation (16).

$$
W S_{\mathrm{F}_{2}}{ }^{N}=\left\{W_{F_{21}}{ }^{N}=0.474, W_{F_{22}}{ }^{N}=0.184, W_{F_{23}}{ }^{N}=0.342\right\}
$$

From equation (16) we deduce that the non-optimal storage of solid waste is mostly contributed by ineffective segregation of solid waste. The second contributing factor to the non-optimal storage of solid waste is inefficient management of solid waste. Thus, the government and nongovernment organizations should always conduct training to the public on SWM. In addition, the DMG should make sure that proper community bins are available at various locations.

\subsubsection{Contribution of the Influential Factors to the Effective Transportation of Solid Waste}

The experts assess the contribution of the factors for the effective transportation of solid waste to give the Judgement Matrix (JM) in table 10.

Table 10. The JM of the Influential Factors for the transportation of Solid Waste.

\begin{tabular}{|c|c|c|c|}
\hline Factor $\left(F_{\text {mu }}\right)$ & $n_{S}{ }^{m n}(\boldsymbol{x})$ & $n_{D}{ }^{m n}(\boldsymbol{x})$ & $n_{U}{ }^{m n}(\boldsymbol{x})$ \\
\hline $\mathrm{F}_{31}$ & 9 & 81 & 5 \\
\hline $\mathrm{F}_{32}$ & 11 & 76 & 8 \\
\hline $\mathrm{F}_{33}$ & 14 & 81 & 0 \\
\hline $\mathrm{F}_{34}$ & 0 & 45 & 50 \\
\hline
\end{tabular}


International Journal of Fuzzy Logic Systems (IJFLS) Vol.8, No.4, October 2018.

We apply equation (6) to establish the IFJTI as shown in table 11.

Table 11. The IFJTI for the Factors Influencing the Transportation of Solid Waste.

\begin{tabular}{|c|c|}
\hline$F_{m u}$ & $\left(\alpha_{A}{ }^{m n}(\boldsymbol{x}), \beta_{A}{ }^{m n}(\boldsymbol{x}), \gamma_{A}{ }^{m n}(\boldsymbol{x})\right)$ \\
\hline$F_{31}$ & $(0.10, \quad 0.85, \quad 0.05)$ \\
\hline$F_{32}$ & $(0.12,0.80,0.08)$ \\
\hline$F_{33}$ & $(0.15, \quad 0.85,0.00)$ \\
\hline$F_{34}$ & $(0.00,0.47,0.53)$ \\
\hline
\end{tabular}

We apply equation (8) to get the normalized weight set of the Influential factors for the transportation of solid waste i.e. equation (17).

$$
W S_{\mathrm{F}_{3}}=\left\{W_{F_{31}}=0.125, W_{F_{32}}=0.16, W_{F_{33}}=0.15, W_{F_{34}}=0.265\right\}
$$

We apply equation (9) to get the normalized weight set of the Influential factors for the transportation of solid waste i.e. equation (18).

$$
W S_{\mathrm{F}_{3}}{ }^{N}=\left\{W_{F_{31}}{ }^{N}=0.179, W_{F_{32}}{ }^{N}=0.229, W_{F_{33}}{ }^{N}=0.214, W_{F_{34}}{ }^{N}=0.378\right\}
$$

The factors contributing to the non-optimal transportation of solid waste in descending order are inadequacy of transportation vehicles, presence of traffic congestion on transportation routes, unsuitability of transportation vehicles and shortage of skilled vehicle operators. The government i.e. DMG should supply enough and suitable transportation vehicles. In addition, transportation network design and vehicle scheduling should be carried out to reduce the traffic congestion.

\subsubsection{Contribution of the Influential Factors to the Effective Disposal of Solid Waste}

The experts assess the contribution of the factors to the effective disposal of solid waste to give the Judgement Matrix (JM) in table 12.

Table 12. The JM of the Influential Factors for the Disposal of Solid Waste.

\begin{tabular}{|c|c|c|c|}
\hline Factor $\left(\mathbf{F}_{\mathbf{m u}}\right)$ & $n_{S}{ }^{m n}(\boldsymbol{x})$ & $n_{D}{ }^{m n}(\boldsymbol{x})$ & $n_{U}{ }^{m n}(\boldsymbol{x})$ \\
\hline $\mathrm{F}_{41}$ & 1 & 76 & 18 \\
\hline $\mathrm{F}_{42}$ & 2 & 82 & 11 \\
\hline $\mathrm{F}_{43}$ & 3 & 75 & 17 \\
\hline $\mathrm{F}_{44}$ & 1 & 79 & 15 \\
\hline
\end{tabular}

We apply equation (6) to establish the IFJTI as shown in table 13. 
International Journal of Fuzzy Logic Systems (IJFLS) Vol.8, No.4, October 2018.

Table 13. The IFJTI for the Factors Influencing the Disposal of Solid Waste.

\begin{tabular}{|c|c|}
\hline$F_{\text {mu }}$ & $\left(\boldsymbol{\alpha}_{A}{ }^{m n}(\boldsymbol{x}), \boldsymbol{\beta}_{A}{ }^{m n}(\boldsymbol{x}), \gamma_{A}{ }^{m n}(\boldsymbol{x})\right)$ \\
\hline$F_{41}$ & $(0.01, \quad 0.80, \quad 0.19)$ \\
\hline$F_{42}$ & $(0.02, \quad 0.86, \quad 0.12)$ \\
\hline$F_{43}$ & $(0.03, \quad 0.79, \quad 0.18)$ \\
\hline$F_{44}$ & $(0.01, \quad 0.83, \quad 0.16)$ \\
\hline
\end{tabular}

We apply equation (8) to get the weight set of the Influential factors for the disposal of solid waste i.e. equation (19).

$W S_{\mathrm{F}_{4}}=\left\{W_{F_{41}}=0.105, W_{F_{42}}=0.08, W_{F_{43}}=0.12, W_{F_{44}}=0.09\right\}$

We apply equation (9) to get the normalized weight set of the Influential factors for the disposal of solid waste i.e. equation (20).

$$
W S_{\mathrm{F}_{4}}{ }^{N}=\left\{W_{F_{41}}{ }^{N}=0.266, W_{F_{42}}{ }^{N}=0.202, W_{F_{43}}{ }^{N}=0.304, W_{F_{44}}{ }^{N}=0.228\right\}
$$

Equation (20) shows that the non-optimal disposal of solid waste at the PKDS is mostly contributed by ineffective safety precautions at the dumping site. Other factors listed in descending order contributing to the non-optimal disposal of solid waste at the site are ineffective security at the dumping site, ineffective treatment of garbage at the dumping site and shortage of compactors or graders at the site. These findings are also supported by [37] who state that the PKDS poses a number of challenges to the solid waste disposal including the site has no infrastructure for environmental protection; there is almost no physical barrier between the waste and the surrounding settlements; waste is all around, inside and outside the site's boundaries; waste is floating in surface water, leading to the formation of leachate; the internal roads are accessible in the dry season; and several hundred scavengers are working, eating and living on the site under inhuman conditions. Thus, the government has the obligation to improve safety precautions and security at the PKDS.

\subsubsection{Overall Contribution of Influential Sub-Factors to the Supply Chain Performance of Solid Waste}

We apply equation (10) to evaluate the contribution of the sub-factors to the Supply Chain performance of solid waste as represented in table 14 .

From table 14 we deduce the overall contribution of sub-factors in descending order to the performance of SWSC in Dar es Salaam City as follows: Availability of collection facilities; Quality of collection containers and conditions of areas around them; Competence and/or hygienic of the collection staff; Segregation of solid waste; Awareness of the public on solid waste management; Safety precautions at the dumping site; Security at the dumping site; Management of solid waste; Treatment of garbage at the dumping site; Adequacy of transportation vehicles; Availability of compactor or graders at the site; Traffic congestion on transportation routes; Availability of community bins (Storage points); Suitability of transportation vehicles; Availability of sweepers and/or sanitation workers and skills of vehicle operators. 
The DMG and other stakeholders are therefore able to identify areas that need urgent attention so as to take corrective measures that would make the SWSC more effective and efficient. Moreover, a sound SWM in Dar es Salaam city entails an optimized solid waste supply chain. This would necessitate a hundred percent collection coverage, optimized storage and transport systems and a hundred percent of the waste being processed on a properly engineered and operated landfill site.

Table 14. Overall Contribution of the Sub-Factors to the Performance of SWSC in Dar es Salaam City.

\begin{tabular}{|c|c|c|c|c|c|}
\hline $\begin{array}{c}\text { Factor } \\
\left(F_{m}\right)\end{array}$ & $\begin{array}{c}\text { Local Weight } \\
\left(W_{F_{m}}{ }^{N}\right)\end{array}$ & $\begin{array}{c}\text { Sub-factor } \\
\left(F_{m n}\right)\end{array}$ & $\begin{array}{c}\text { Local Weight } \\
\left(W_{F_{m n}}{ }^{N}\right)\end{array}$ & $\begin{array}{c}\text { Overall Performance } \\
\left(W_{F_{m}}{ }^{N} \cdot W_{F_{m n}}{ }^{{ }^{n}}\right)\end{array}$ & Rank \\
\hline \multirow[t]{5}{*}{$F_{1}$} & \multirow[t]{5}{*}{0.205} & $F_{11}$ & 0.078 & $W_{F_{1}}{ }^{N} \cdot W_{F_{11}}{ }^{N}=0.016$ & 16 \\
\hline & & $F_{12}$ & 0.157 & $W_{F_{1}}{ }^{N} \cdot W_{F_{12}}{ }^{N}=0.032$ & 14 \\
\hline & & $F_{13}$ & 0.212 & $W_{F_{1}}^{N} \cdot W_{F_{13}}{ }^{N}=0.043$ & 12 \\
\hline & & $\mathrm{F}_{14}$ & 0.095 & $W_{F_{1}}^{N} \cdot W_{F_{14}}{ }^{N}=0.019$ & 15 \\
\hline & & $F_{15}$ & 0.458 & $W_{F_{1}}{ }^{N} \cdot W_{F_{15}}{ }^{N}=0.094$ & 2 \\
\hline \multirow[t]{3}{*}{$F_{2}$} & \multirow[t]{3}{*}{0.178} & $F_{21}$ & 0.474 & $W_{F_{2}}{ }^{N} \cdot W_{F_{21}}{ }^{N}=0.084$ & 4 \\
\hline & & $F_{22}$ & 0.184 & $W_{F_{2}}{ }^{N} \cdot W_{F_{22}}{ }^{N}=0.033$ & 13 \\
\hline & & $F_{23}$ & 0.342 & $W_{F_{2}}{ }^{N} \cdot W_{F_{23}}{ }^{N}=0.061$ & 9 \\
\hline \multirow[t]{4}{*}{$F_{3}$} & \multirow[t]{4}{*}{0.384} & $F_{31}$ & 0.179 & $W_{F_{3}}{ }^{N} \cdot W_{F_{31}}{ }^{N}=0.069$ & 7 \\
\hline & & $\mathrm{F}_{32}$ & 0.229 & $W_{F_{3}}^{N} \cdot W_{F_{32}}{ }^{N}=0.088$ & 3 \\
\hline & & $F_{33}$ & 0.214 & $W_{F_{3}}{ }^{N} \cdot W_{F_{33}}{ }^{N}=0.082$ & 5 \\
\hline & & $\mathrm{F}_{34}$ & 0.378 & $W_{F_{3}}{ }^{N} \cdot W_{F_{3}}{ }^{N}=0.145$ & 1 \\
\hline \multirow[t]{4}{*}{$\mathrm{F}_{4}$} & \multirow[t]{4}{*}{0.233} & $F_{41}$ & 0.266 & $W_{F_{4}}^{N} \cdot W_{F_{41}}{ }^{N}=0.062$ & 8 \\
\hline & & $\mathrm{F}_{42}$ & 0.202 & $W_{F_{4}}^{N} \cdot W_{F_{42}}{ }^{N}=0.047$ & 11 \\
\hline & & $F_{43}$ & 0.304 & $W_{F_{4}}{ }^{N} \cdot W_{F_{43}}{ }^{N}=0.071$ & 6 \\
\hline & & $F_{44}$ & 0.228 & $W_{F_{4}}{ }^{N} \cdot W_{F_{4}}{ }^{N}=0.053$ & 10 \\
\hline
\end{tabular}

\section{CONCLUSIONS}

SWM is becoming a serious concern in Dar es Salaam City due to the ineffective Collection, Storage, Transportation and Disposal of solid waste. This implies that significant proportion of waste generated end up in the environment in an unacceptable ways of disposal which accentuates environmental and public health risks. In this study, an Intuitionistic Fuzzy Model is applied to analyse the performance of the supply chain for the solid waste in Dar es Salaam city. The analysis is carried out as follows. Firstly, the literature review and expert opinions are used to identify the nodes (factors) that influence the supply chain performance of the solid waste. Secondly, we apply IFS to determine the contribution of each factor and/or sub-factor to the supply chain performance. The assessment results reveal that the supply chain performance for solid waste in DSM city is affected by the following nodes as listed in descending order: Storage of solid waste, Collection of solid waste, Disposal of solid waste and Transportation of solid 
waste. Thus, more deliberate efforts from all stakeholders are needed to improve the supply chain performance for solid waste in Dar es Salaam city. More importantly, the model based on IFS can be used for analysis of supply chain performance of solid waste in other Municipalities and cities. Our future research is to carry out an in-depth study to assess the performance of the reverse logistics for glass materials in Dar es Salaam city.

\section{REFERENCES}

[1] R. Breeze. 2012. "Municipal Solid Waste Management in Dar es Salaam: Draft Baseline Analysis".[Online]. Available: World Bank, http://siteresources.worldbank.org. [Accessed August 23, 2018].

[2] K.O. Agyeman, P.B. Cobbinah, and M. Addaney. In Press. "Locating the role of urbanites in solid waste management in Ghana”. Environmental Development.

[3] A.E. Adeniran, A.T. Nubi and A.O. Adelopo, (2017) "Solid waste generation and characterization in the University of Lagos for a sustainable waste management”. Waste Management, Vol.67, pp. 3-10.

[4] Y.Liu, P. Xing. and J. Liu, (2017) "Environmental performance evaluation of different municipal solid waste management scenarios in China". Resources, Conservation and Recycling, Vol.125, pp. 98-106.

[5] D.M.Simatele, S. Dlamini. and N.S. Kubanza, (2017) "From informality to formality: Perspectives on the challenges of integrating solid waste management into the urban development and planning policy in Johannesburg, South Africa". Habitat International, Vol. 63, pp.122-130.

[6] A. Maalouf and M. El-Fadel. In Press. "Effect of a food waste disposer policy on solid waste and wastewater management with economic implications of environmental externalities". Waste Management.

[7] A. Soni, D. Patil. and K. Argade, (2016) "Municipal solid waste management". Procedia Environmental Sciences, Vol.35, pp. 119-126.

[8] R. Chifari, A. Renner, S.L. Piano, M. Ripa, S.G.F. Bukkens and M. Giampietro, (2017) "Development of a Municipal solid waste management decision support tool for Naples Italy". Journal of Cleaner Production, Vol.161, pp.1032-1043.

[9] J.M. Fernández-González, A.L. Grindlay, M.I. Rodríguez-Rojas, M. Zamorano. and F. SerranoBernardo, (2015) "Economic and environmental review of waste-to-energy systems for Municipal solid waste management in medium and small Municipalities". Waste Management, Vol. 67, pp. 360374.

[10] J. Zhu. and G. Huang, (2017) "Contract-out planning of solid waste management system under uncertainty: Case study on Toronto, Ontario, Canada". Journal of Cleaner Production, Vol. 168, pp. 1370-1380.

[11] B. Khoshnerisan, S. Rafiee, M. Tabatabaei, H. Ghanavati, S.S. Mohtasebi. and M.A. Rajaeifar, (2017) "Response to Prognostication of energy use and environmental impacts for recycle system of Municipal solid waste management”. Journal of Cleaner Production, Vol. 164, pp. 1376-1379.

[12] G. Liu, Y. Hao, L. Dong, Z. Yang, Y. Zhang and S. Ulgiati, (2017). "An emergy-LCA analysis of Municipal solid waste management”. Resources, Conservation and Recycling, Vol. 120, pp. 131-143.

[13] M.A. Rajaeifar, H. Ghanavati, B.B. Dashti, R. Heijungs, M. Aghbashlo. and M. Tabatabaei, (2017) "Electricity generation and GHG emission reduction potentials through different Municipal solid 
waste management technologies: A comparable review". Renewable and Sustainable Energy Reviews, Vol. 79, pp. 414-439.

[14] A. Kumar and S.R. Samadder. In Press. "A review on technological options of waste to energy for effective management of Municipal solid waste". Waste Management.

[15] M.I.M. Ibrahim. and N.A.E.M. Mohamed, (2016) "Towards Sustainable Management of Solid Waste in Egypt”. Procedia Environmental Sciences, Vol.34, pp. 336-347.

[16] A.V.Melaré, S.M.González, K. Faceli. and V. Casadei, (2017) “Technologies and decision support systems to aid solid waste management: a systematic review". Waste Management, Vol.59, pp. 567584.

[17] N. Gupta, K.K. Yadav. and V. Kumar, (2015) "A review on current status of municipal solid waste management in India”. Journal of Environmental Sciences, Vol. 37, pp. 206-217.

[18] R.M. Deus, R.A.G. Battistelle. and G.H.R. Silva, (2017) "Current and future environmental impact of household solid waste management scenarios for a region of Brazil: Carbon dioxide and energy analysis". Journal of Cleaner Production, Vol.155, pp. 218-228.

[19] P. Sukholtthaman, K. Shirahada and A. Sharp. In Press. "Toward effective multi-sector partnership: A case of municipal solid waste management service provision in Bangkok, Thailand". Kasetsart Journal of Social Sciences.

[20] Z.Wang, Z.Yao, S. Liu and Z. Xu, (2014) "Direct clustering analysis based on intuitionistic fuzzy implication”. Applied Soft Computing, Vol. 23, pp. 1-8.

[21] H.S. Tooranloo and A.S. Ayatollah, (2016) "A model for failure mode and effects analysis based on intuitionistic fuzzy approach”. Applied Soft Computing, Vol.49, pp. 238-247.

[22] Y. Liu, J.W. Bi and Z.P. Fan, (2017) "Ranking products through online reviews: A method based on sentiment analysis technique and intuitionistic fuzzy set theory”. Information Fusion, Vol.36, pp. 149161.

[23] R.Peijia, X. Zeshui, L. Huchang and Z. Xiao-Jun, (2017) "A thermodynamic method of intuitionistic fuzzy MCDM to assist the hierarchical medical system in China”. Information Sciences, Vol. 420, pp. 490-504.

[24] Z. Pei, (2015) "Intuitionistic fuzzy variables: Concepts and applications in decision making". Expert Systems with Applications, Vol.42, No.5, pp. 9033-9045.

[25] L. Huchang, M. Qiong. and X. Zeshui, (2016) “An intuitionistic fuzzy multiplicative best-worst method for multi-criteria group decision making”. Information Sciences, Vol.374, pp. 224-239.

[26] K. Govindan, R. Khodaverdi and A. Vafadarnikjoo, (2015) "Intuitionistic fuzzy based DEMATEL method for developing green practices and performances in a green supply chain”. Expert Systems with Applications, Vol. 42, No.20, pp. 7207-7220.

[27] J.Wang and Y.Sun, (2012) "The intuitionistic fuzzy sets on evaluation of risks in projects of energy management contract”. Systems Engineering Procedia, Vol.3, pp. 30-35.

[28] S. Long and S. Geng, (2015) "Decision framework of photovoltaic module selection under intervalvalued intuitionistic fuzzy environment". Energy Conversion and Management, Vol. 106, pp. 12421250 . 
[29] M. Kucukvar, S. Gumus, G. Egilmez and O. Tatari, (2014) "Ranking the sustainability performance of pavements: An intuitionistic fuzzy decision making method". Automation in Construction, Vol.40, pp. 33-43.

[30] M.C. Wu and T.Y. Chen, (2011) "The ELECTRE multicriteria analysis approach based on Atanassov's intuitionistic fuzzy sets”. Expert Systems with Applications, Vol.35, No. 10, pp.1231812327.

[31] Y.Wu, S. Geng, H., Xu and H. Zhang, (2014) "Study of decision framework of wind farm project plan selection under intuitionistic fuzzy set and fuzzy measure environment”. Energy Conversion and Management, Vol.87, pp. 274-284.

[32] G. Büyüközkan, S.Güleryüz and B. Karpak, (2017) "A new combined IF-DEMATEL and IF-ANP approach for CRM partner evaluation”. International Journal of Production Economics, Vol.191, pp.194-206.

[33] E.K. Zavadskas, J. Antucheviciene, S.H.R. Hajiagha and S.S. Hashemi, (2014)“Extension of weighted aggregated sum product assessment with interval-valued intuitionistic fuzzy numbers". Applied Soft Computing, Vol. 24, pp. 1013-1021.

[34] K. Atanassov, (1986) “Intuitionistic Fuzzy Sets”. Fuzzy Sets and Systems, Vol.20, No. 1, pp. 87-96.

[35] K. Atanassov, G. Gargov, (1995) “On the Intuitionistic Fuzzy Logic Operations”. Notes on Intuitionistic Fuzzy Sets, Vol.1, No.1, pp. 1-4.

[36] K. Atanassov, (1999) “Intuitionistic Fuzzy Sets: Theory and Applications”. Berlin: Springer.

[37] H. Huisman, H. Breukelman and B. Keesman, (2016) "Expert Mission on Integrated Solid Waste Management (ISWM) to Dar es Salaam".[Online]. Available: https://www.rvo.nl. [Accessed August 23, 2018].

\section{Biographical Notes}

Erick P. Massami holds a PhD in Logistics Engineering and Management from Dalian Maritime University, China. Currently, he is a Senior Lecturer in Logistics and Transport Studies at Dar es Salaam Maritime Institute, Tanzania. He has published many research papers in various international journals. His research interests include Supply Chain Modelling and Optimisation, Computational Intelligence, Scheduling, and Economic Investment Planning.

Malima M. Manyasi has a Master Degree in Information Technology from OWL University of Applied Sciences, Germany. Currently, he is working as an Assistant Lecturer at Dar es Salaam Maritime Institute, Tanzania. His research interests focus on Artificial Intelligence, System Modelling, Machine Learning, Maritime Transport, and Data Mining.

Eliamin A. Kassembe is a Lecturer at Dar es Salaam Maritime Institute, Tanzania. He holds a BSc Degree in Maritime Navigation with Specialization in Maritime Technology from the University of Plymouth, UK. He holds also an MSc Degree in Maritime Operations from Liverpool John Moores University, UK and a PhD in Transport Planning and Management from Shanghai Maritime University, China. Eliamin A. Kassembe is a dedicated researcher specializing in maritime transportation, economics and logistics.
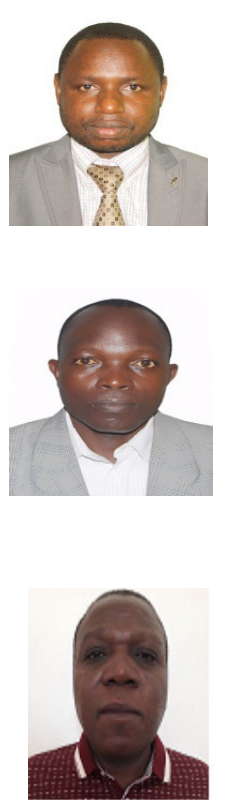